\title{
New systemic treatment options in mycosis fungoides and Sézary syndrome
}

\author{
Magdalena Seidl-Philipp (D) · Van Anh Nguyen
}

Received: 14 April 2020 / Accepted: 5 May 2020 / Published online: 20 May 2020

(C) The Author(s) 2020

\begin{abstract}
Summary Cutaneous $\mathrm{T}$ cell lymphomas (CTCL) are a heterogeneous group of rare non-Hodgkin lymphomas. The most common type of CTCL is Mycosis fungoides (MF). Much less common but clinically and histopathologically related to MF is Sézary syndrome (SS). CTCL are incurable and associated with a reduced quality of life. While early stage MF has a good prognosis and is usually treated with skin directed therapies, advanced-stages require systemic therapies, including retinoids, interferon, cytotoxic chemotherapeutic drugs, low-dose methotrexate, histone deacetylase inhibitors and alemtuzumab. However, relapses are frequent and long-term remissions are achieved only in few cases, e.g. with allogenic stem cell transplantation. In recent years, new therapeutic options have evolved by the approval of brentuximab vedotin and mogamulizumab. Both recently approved therapies demonstrated superiority with regard to overall response rate and progression free survival over traditional systemic therapies. Other promising treatments such as lacutamab and PD1/L-1 inhibitors are in the pipeline, and more therapeutic agents are currently investigated in clinical trials.
\end{abstract}

Keywords Cutaneous T-cell lymphoma . Brentuximab vedotin - Mogamulizumab . Lacutamab · PD-1/L-1 inhibitors

\footnotetext{
M. Seidl-Philipp, MD $(\bowtie) \cdot$ V. A. Nguyen, MD Department of Dermatology, Venereology and Allergology, Medical University of Innsbruck, Anichstraße 35, 6020 Innsbruck, Austria magdalena.philipp@i-med.ac.at

V. A. Nguyen, MD

van.nguyen@i-med.ac.at
}

\section{Introduction}

Cutaneous $\mathrm{T}$ cell lymphomas (CTCL) are a heterogeneous group of rare non-Hodgkin lymphomas characterized by infiltration of neoplastic T lymphocytes to the skin. The most common type of CTCL is mycosis fungoides (MF). Much less common but clinically and histopathologically related to MF is Sézary syndrome (SS) [1]. Reported age-adjusted incidence rates per 100,000 person-years in the United States (US) between 2005 and 2008 were 0.55 for MF and 0.01 for SS [2]. The clinical presentation and prognosis of MF vary widely and depend on clinical stage, ranging from limited skin involvement with patches and plaques to severe illness with ulcerated skin tumors, systemic involvement and death [3]. SS, which is more aggressive and clinically staged IVA-IVB [4], is defined by pruritic erythroderma, generalized lymphadenopathy and leukemic involvement [1]. CTCL are incurable and associated with a reduced quality of life $[3,5]$. While early stage MF has a good prognosis and is usually treated with skin directed therapies, median survival ranges from 4.7 to 1.4 years in advanced stages of MF and SS (clinical stage IIB-IVB) [6]. Systemic therapies are then required, including retinoids, interferon alpha, cytotoxic chemotherapeutic drugs, low-dose methotrexate, histone deacetylase inhibitors (vorinostat, romidepsin, belinostat) and alemtuzumab [3]. However, relapses are frequent and long-term remissions are achieved only in few cases, e.g. with allogenic stem cell transplantation [7]. In recent years new therapeutic options have evolved. These are discussed in detail in the following article.

\section{Brentuximab vedotin}

CD30, a cell surface receptor, is uniformly expressed in Hodgkin lymphoma (HL) and anaplastic large cell 
Table 1 Ongoing studies with PD-1/L-1 inhibitors in mycosis fungoides (MF)/(SS) Sézary syndrome as listed on ClinicalTrials.gov (accessed on March 30th 2020) [18]

\begin{tabular}{|c|c|c|c|c|c|}
\hline NCT identifier & Official title & Phase & $\begin{array}{l}\text { Recruitment } \\
\text { status }\end{array}$ & Conditions & Interventions \\
\hline NCT03240211 & $\begin{array}{l}\text { Pembrolizumab combined with Decitabine and Pralatrexate } \\
\text { in PTCL and CTCL }\end{array}$ & Phase lb & Recruiting & CTCL, PTCL & $\begin{array}{l}\text { Pembrolizumab, } \\
\text { Decitabine, Pralatrexate }\end{array}$ \\
\hline NCT03385226 & $\begin{array}{l}\text { Pembrolizumab combined with radiotherapy in patients } \\
\text { with relapsed, refractory, specified stages of cutaneous } \\
\text { T-cell Lymphoma (CTCL) Mycosis Fungoides (MF)/Sezary } \\
\text { Syndrome (SS) (PORT) }\end{array}$ & Phase II & Recruiting & MF/SS & $\begin{array}{l}\text { Pembrolizumab + radio- } \\
\text { therapy }\end{array}$ \\
\hline NCT03617224 & $\begin{array}{l}\text { Pembrolizumab and Total Skin Electron Beam Radiotherapy } \\
\text { in Mycosis Fungoides and Sezary Syndrome }\end{array}$ & Phase I & Recruiting & MF/SS & Pembrolizumab + TSEBT \\
\hline NCT03063632 & $\begin{array}{l}\text { Pembrolizumab and Interferon Gamma- } 1 \mathrm{~b} \text { in treating } \\
\text { patients with stage IB-IVB relapsed or refractory Mycosis } \\
\text { Fungoides and Sezary Syndrome }\end{array}$ & Phase II & $\begin{array}{l}\text { Active, not } \\
\text { recruiting }\end{array}$ & $\begin{array}{l}\mathrm{MF} / \mathrm{SS} \text { and } \\
\text { others }\end{array}$ & $\begin{array}{l}\text { Pembrolizumab + Inter- } \\
\text { feron Gamma-1b }\end{array}$ \\
\hline NCT03695471 & $\begin{array}{l}\text { Pembrolizumab in treating patients with stage IB-IV Myco- } \\
\text { sis Fungoides }\end{array}$ & Phase II & Recruiting & $\mathrm{MF} / \mathrm{SS}$ & Pembrolizumab \\
\hline NCT03598998 & $\begin{array}{l}\text { Pembrolizumab and Pralatrexate in treating patients with } \\
\text { relapsed or refractory peripheral T-Cell Lymphomas }\end{array}$ & Phase I/II & Recruiting & $\begin{array}{l}\text { MF and } \\
\text { others }\end{array}$ & $\begin{array}{l}\text { Pembrolizumab + Prala- } \\
\text { trexate }\end{array}$ \\
\hline NCT03278782 & $\begin{array}{l}\text { Pembrolizumab (MK-3475) in combination with Ro- } \\
\text { midepsin }\end{array}$ & Phase I/II & Recruiting & $\begin{array}{l}\text { MF and } \\
\text { others }\end{array}$ & $\begin{array}{l}\text { Pembrolizumab + Ro- } \\
\text { midepsin }\end{array}$ \\
\hline NCT02581631 & $\begin{array}{l}\text { Nivolumab in combination with Brentuximab Vedotin to } \\
\text { treat Non-Hodgkin Lymphomas (CheckMate 436) }\end{array}$ & Phase I/II & $\begin{array}{l}\text { Active, not } \\
\text { recruiting }\end{array}$ & $\begin{array}{l}\text { MF/SS and } \\
\text { others }\end{array}$ & Nivolumab + BV \\
\hline NCT02643303 & $\begin{array}{l}\text { In Situ Vaccination with Tremelimumab and iv Durvalumab } \\
\text { plus PolylCLC in subjects with advanced, measurable, } \\
\text { biopsy-accessible cancers }\end{array}$ & Phase I/II & Recruiting & $\begin{array}{l}\text { CTCL and } \\
\text { others }\end{array}$ & $\begin{array}{l}\text { Durvalumab, Tremeli- } \\
\text { mumab, Poly ICLC }\end{array}$ \\
\hline NCT03011814 & $\begin{array}{l}\text { Durvalumab with or without Lenalidomide in treating pa- } \\
\text { tients with relapsed or refractory cutaneous or peripheral } \\
\text { T cell lymphoma }\end{array}$ & Phase I/II & Recruiting & $\begin{array}{l}\text { MF/SS and } \\
\text { others }\end{array}$ & Durvalumab, Lenalidomid \\
\hline NCT03357224 & $\begin{array}{l}\text { PARCT: Atezolizumab in relapsed/refractory cutaneous } \\
\text { T Cell lymphoma (CTCL) (PARCT) }\end{array}$ & Phase II & Recruiting & CTCL & Atezolizumab \\
\hline NCT03905135 & $\begin{array}{l}\text { Interleukin-15 (IL-15) in combination with Avelumab } \\
\text { (Bavencio) in relapsed/refractory mature T-cell malig- } \\
\text { nancies }\end{array}$ & Phase I & Recruiting & $\begin{array}{l}\text { MF/SS and } \\
\text { others }\end{array}$ & rhlL-15, Avelumab \\
\hline
\end{tabular}

lymphoma (ALCL) [8]. In CTCL CD30 expression is commonly seen in primary cutaneous anaplastic large-cell lymphoma (pc-ALCL) and lymphomatoid papulosis [1] and less frequently in MF and SS at various levels, ranging from 20-40\% [9-11]. Brentuximab vedotin (BV) is an anti-CD30 antibody conjugated to the cytotoxic antitubulin agent monomethyl auristatin E (MMAE). The interaction between this complex and the CD30 ligand on lymphocytes leads to internalization into the cell where MMAE is released and causes an interruption of the microtubule network, inducing cell-cycle arrest and apoptosis. In addition, a small fraction of MMAE is released from CD30+ cells, killing neighboring cells in the tumor microenvironment in a CD30-independent manner [12]. In November 2017 the US Food and Drug Administration (FDA) and the European Medicines Agency (EMA) approved BV for patients with CD30+ CTCL that have received at least one systemic therapy $[13,14]$, based on the results of the ALCANZA study [15]. In this phase 3 trial, 97 patients with CD30+ MF and 31 patients with pcALCL pretreated with at least one systemic therapy or radiotherapy were randomly assigned to BV (intravenously $1.8 \mathrm{mg} / \mathrm{kg}$ every 3 weeks for up to 16 cycles) or to physician's choice (oral methotrexate 5-50 mg qw or oral bexarotene $\left.300 \mathrm{mg} / \mathrm{m}^{2} \mathrm{qd}\right)$. CD30 expres- sion of at least $10 \%$ of malignant cells or lymphoid infiltrate in skin biopsies was required. The primary endpoint was the percentage of patients achieving an overall response rate (ORR) persistent for at least 4 months (ORR4). This was reached in $50 \%$ of the MF patients in the BV group and in $10 \%$ in the physician's choice group. Responses to BV were seen in all clinical stages, albeit patients with SS were excluded from this study and approximately $3 / 4$ of included patients had lower grade disease (stage IA-IIB). The progression free survival (PFS) was 15.9 months in the BV arm versus 3.5 months in the control arm. Side effects were similar to previous reports. The most common adverse event (AE) observed in the BV group was peripheral neuropathy (67\%), which usually resolved after treatment discontinuation. Grade 3-4 AEs were reported in $41 \%$ of patients in the BV group and in $47 \%$ in the physician's choice group. One death was considered to be treatment related in the BV group. In sum, this study showed efficacy of BV in the treatment of refractory or relapsed CD30+ MF with CD30 expression levels of at least 10\% [15]. Notably, in two smaller phase 2 trials the efficacy of BV was also demonstrated in CD30+ SS as well as in MF/SS with CD30 expression levels below 10\% [16, 17], although response in patients with CD30 expression levels be- 
low $5 \%$ was poor (17\%) [16], suggesting that response to BV appears to be independent of CD30 expression only in patients with expression levels over $5-10 \%$. Ongoing studies are examining BV in combination with other substances like nivolumab, romidepsin and lenalidomide in CTCL patients (Tables 1 and 2; [18]).

\section{Mogamulizumab}

C-C chemokine receptor type 4 (CCR4), a chemokine receptor important for $\mathrm{T}$ cell migration into the skin, is highly expressed on malignant T-cells and Tregs in MF and SS [19, 20]. Mogamulizumab is a CCR4-directed, defucosylated, monoclonal antibody that induces antibody dependent cellular cytotoxicity (ADCC) against CCR4+ malignant $\mathrm{T}$ cells and Tregs when binding to CCR4 [21]. In 2018 the FDA and the EMA approved mogamulizumab for relapsed or refractory MF and SS that has been pretreated with at least one systemic therapy $[22,23]$. The basis of this approval was a phase 3 trial (MAVORIC) involving 372 patients with relapsed or refractory pretreated MF or SS [24]. Patients were stratified by CTCL subtype and clinical stage and were randomly assigned to mogamulizumab in the approved dose of $1.0 \mathrm{mg} / \mathrm{kg}$ intravenously once weekly for 4 weeks, followed by further cycles every other week, or to FDA approved vorinostat $400 \mathrm{mg}$ daily. The primary end point was PFS, which was 7.7 months in the mogamulizumab group compared to 3.1 months in the vorinostat group. ORR to mogamulizumab was $28 \%$ versus $5 \%$ to vorinostat. In SS patients, the response rate to mogamulizumab was higher than in MF patients: $37 \%$ versus $21 \%$. Stage dependent response to mogamulizumab was most significant in clinical stage IV: $36 \%$ versus $19 \%$ in stage IB or IIA. Compartment response was best in blood $(68 \%)$, followed by skin (42\%), lymph nodes (17\%) and viscera $(0 \%)$. The most common AEs of mogamulizumab were infusion related reactions, drug rash, diarrhea and fatigue. Grade 3-4 AEs were reported in $41 \%$ of patients, most frequently pyrexia and cellulitis. A total of $19 \%$ discontinued treatment due to toxicity. Two treatmentrelated deaths occurred, one case due to septicemia and another due to polymyositis. Overall, the safety profile was manageable and in accordance with previous reports. In brief, this study underscores the efficacy of mogamulizumab, particularly in SS and advanced stage MF [24]. However, patients with large cell transformation-a histological feature observed in $10-20 \%$ of $\mathrm{MF} / \mathrm{SS}$ patients and associated with poor outcomes [10]-were excluded from this study. A phase 2 study evaluating mogamulizuab in combination with total skin electron beam therapy (TSEBT) in CTCL patients is expected to enroll in May 2020 (MOGAT, NCT04128072) [18].

\section{Future perspectives}

\section{Lacutamab (IPH4102)}

Lacutamab is a first-in-class monoclonal antibody targeting KIR3DL2, a cell surface protein that is frequently expressed by malignant $\mathrm{T}$ cells in CTCL, but not on normal CD4+ cells. Especially in SS, more than $85 \%$ of patients exhibit KIR3DL2 expression [25]. Lacutamab selectively depletes KIR3DL2+ cells through ADCC and phagocytosis [26]. In 2019, results of a phase 1 trial investigating the safety and activity of lacutamab in MF and SS were published [27]. In this study, 35 patients with SS, eight patients with MF and one patient with CTCL not otherwise specified were enrolled. Patients received at least two prior lines of treatment. The primary endpoint was the incidence of dose-limiting toxicities (grade 3 AEs or higher). Of note, no patient experienced such doselimiting AEs. The most common grade 1-2 AEs were peripheral edema $(27 \%)$ and fatigue $(20 \%)$. The most common grade 3 toxicity was lymphopenia seen in $7 \%$ of patients. Only $9 \%$ of patients had to permanently discontinue treatment due to toxicity. ORR was $36.4 \%$ in all patients and specifically $43 \%$ in SS patients. In all patients, median DOR was 13.8 months and median PFS was 8.2 months, compared to 11.7 months in SS patients [28]. As a result, lacutamab received fast-track designation from the FDA for the treatment of patients with relapsed or refractory SS pretreated with at least two systemic therapies. Despite these promising results, lacutamab seems not to be effective in SS patients with large cell transformation as none of those patients showed a response. Currently, lacutamab is being investigated in a phase 2 study to evaluate the clinical activity and safety of lacutamab in MF, SS and other KIR3DL2 expressing T-cell lymphomas (TELLOMAK, NCT03902184).

\section{$P D-1 / L-1$ inhibitors}

It has been shown that PD-1 expression is high during early stage MF and that of PD-L1 in advanced stages with large cell transformation, likely contributing to immune evasion of malignant T cells [28]. PD$1 / \mathrm{L}-1$ inhibitors prevent PD-1 from binding to its ligand, allowing $\mathrm{T}$ cell-mediated destruction of malignant lymphocytes [29]. Results of a phase 2 trial of pembrolizumab in the treatment of CTCL have been recently published [30]. Herein, 24 pretreated patients with advanced MF and SS received pembrolizumab $2 \mathrm{mg} / \mathrm{kg}$ every 3 weeks. The response rate was $56 \%$ in $\mathrm{MF}$ and $27 \%$ in SS (overall $38 \%$ ). The median duration of response (DOR) was not reached after a median follow-up time of 58 weeks. Biomarker analysis showed no differences that might explain the discrepancy in response rates between MF and SS. The safety profile was consistent with other studies using PD-1 inhibitors. In $53 \%$ of SS patients, a transient wors- 
Table 2 A selection of ongoing studies in mycosis fungoides (MF)/Sézary syndrome (SS) with other interesting substances not cited in the text, as listed on ClinicalTrials.gov (accessed on March 30th 2020) [18]

\begin{tabular}{|c|c|c|c|c|c|}
\hline NCT identifier & Official title & Phase & $\begin{array}{l}\text { Recruitment } \\
\text { status }\end{array}$ & Conditions & Interventions \\
\hline NCT03713320 & $\begin{array}{l}\text { Cobomarsen (MRG-106) vs. active comparator in } \\
\text { subjects with Mycosis Fungoides (SOLAR) }\end{array}$ & Phase 2 & Recruiting & MF & Cobomarsen vs. Vorinostat \\
\hline NCT02953301 & $\begin{array}{l}\text { Resminostat for maintenance treatment of patients } \\
\text { with advanced stage Mycosis Fungoides (MF) or } \\
\text { Sézary Syndrome (SS) (RESMAIN) }\end{array}$ & Phase 2 & Recruiting & MF/SS & Resminostat vs. Placebo \\
\hline NCT02783625 & $\begin{array}{l}\text { Duvelisib in combination with either Romidepsin or } \\
\text { Bortezomib in relapsed/refractory T-cell Lymphomas }\end{array}$ & Phase 1 & Recruiting & $\begin{array}{l}\text { CTCL and } \\
\text { others }\end{array}$ & $\begin{array}{l}\text { Duvelisib + Romidepsin or Duvelisib + } \\
\text { Bortezomib }\end{array}$ \\
\hline NCT01871727 & $\begin{array}{l}\text { E7777 in persistent and recurrent cutaneous T-Cell } \\
\text { Lymphoma }\end{array}$ & Phase 3 & Recruiting & MF/SS & $\begin{array}{l}\text { E7777 (fusion protein that combines } \\
\text { the IL-2 receptor binding domain with } \\
\text { diphtheria toxin fragments; related to } \\
\text { Denileukin Diftitox) }\end{array}$ \\
\hline NCT02232516 & $\begin{array}{l}\text { Romidepsin and Lenalidomide in treating patients } \\
\text { with previously untreated peripheral T-Cell Lym- } \\
\text { phoma }\end{array}$ & Phase 2 & Recruiting & $\begin{array}{l}\text { MF/SS and } \\
\text { others }\end{array}$ & Romidepsin + Lenalidomid \\
\hline NCT00466921 & $\begin{array}{l}\text { Lenalidomide in treating patients with relapsed } \\
\text { Mycosis Fungoides/Sezary Syndrome }\end{array}$ & Phase 2 & $\begin{array}{l}\text { Active, not } \\
\text { recruiting }\end{array}$ & MF/SS & Lenalidomid \\
\hline NCT03409432 & $\begin{array}{l}\text { Brentuximab Vedotin and Lenalidomide in treating } \\
\text { patients with Stage IB-IVB relapsed or refractory } \\
\text { T-Cell Lymphoma }\end{array}$ & Phase 2 & Recruiting & $\begin{array}{l}\text { CTCL and } \\
\text { others }\end{array}$ & BV + Lenalidomid \\
\hline NCT02616965 & $\begin{array}{l}\text { Romidepsin combined with Brentuximab Vedotin in } \\
\text { cutaneous T-cell Lymphoma }\end{array}$ & Phase 1 & Recruiting & CTCL & Romidepsin + BV \\
\hline
\end{tabular}

ening of erythroderma and pruritus was observed. However, this side effect did not result in treatment discontinuation in any patient. Taken together, this study demonstrated durable responses and a favorable safety profile of pembrolizumab in pretreated MF and SS patients [30]. Ongoing studies are evaluating the efficacy of several PD1- and PD-L1 inhibitors such as pembrolizumab, nivolumab, durvalumab, atezolizumab and avelumab, either alone or in combination with other agents or radiation to treat MF and SS (Table 1).

\section{Other promising future therapies}

Due to limited space this article only briefly refers to duvelisib (IPI-145), an oral inhibitor of phosphatidylinositol 3-kinase (PI3K) $-\delta / \gamma$ isoforms. Its inhibition directly blocks malignant $\mathrm{T}$-cell growth and modulates nonmalignant immune cells. Results of a phase I study investigating the efficacy and safety of duvelisib in relapsed PTCL and CTCL were recently published and revealed encouraging data with clinical activity and acceptable safety profile [31]. Several other agents are currently being assessed in MF/SS. A selection of these is summarized in Table 2.

\section{Conclusion}

The approval of BV and mogamulizumab for advanced and refractory MF and SS has broadened the therapeutic spectrum for this incurable disease group with poor prognosis. Lacutamab and PD-1/L-1 inhibitors have demonstrated encouraging results in phase 1 and phase 2 trials. More promising novel therapeutic agents are currently undergoing clinical trial and will continue to expand the therapeutic options available in the management of advanced-stage MF und SS.

\section{Take home message}

The approval of BV and mogamulizumab has broadened the therapeutic spectrum for advanced and refractory MF/SS. Other potential therapies such as lacutamab and PD-1/L-1 inhibitors have shown promise.

Funding Open access funding provided by University of Innsbruck and Medical University of Innsbruck.

Conflict of interest $\mathrm{M}$. Seidl-Philipp reports financial support from BMS outside the submitted work. V.A. Nguyen reports speaker's honoraria and/or consultancy fees from Amgen, BMS, GSK, Merck, MSD, Novartis, Pierre Fabre, Roche and Takeda outside the submitted work.

Open Access This article is licensed under a Creative Commons Attribution 4.0 International License, which permits use, sharing, adaptation, distribution and reproduction in any medium or format, as long as you give appropriate credit to the original author(s) and the source, provide a link to the Creative Commons licence, and indicate if changes were made. The images or other third party material in this article are included in the article's Creative Commons licence, unless indicated otherwise in a credit line to the material. If material is not included in the article's Creative Commons licence and your intended use is not permitted by statutory regulation or exceeds the permitted use, you will need to obtain permission directly from the copyright holder. To view a copy of this licence, visit http://creativecommons.org/licenses/by/4.0/. 


\section{References}

1. Willemze R, Cerroni L, Kempf W, et al. The 2018 update of the WHO-EORTC classification for primary cutaneous lymphomas. Blood. 2019;133(16):1703-14.

2. Imam MH, Shenoy PJ, Flowers CR, et al. Incidence and survival patterns of cutaneous T-cell lymphomas in the United States. LeukLymphoma. 2013;54(4):752-9.

3. Trautinger F, Eder J, Assaf C, et al. European organisation for research and treatment of cancer consensus recommendations for the treatment of mycosis fungoides/Sézary syndrome-update 2017. Eur J Cancer. 2017;77:57-74.

4. Olsen E, Vonderheid E, Pimpinelli N, et al. Revisions to the staging and classification of mycosis fungoides and Sezary syndrome: a proposal of the International Society for $\mathrm{Cu}$ taneous Lymphomas (ISCL) and the cutaneous lymphoma task force of the European Organization of Research and Treatment of Cancer (EORTC). Blood. 2007;110(6):1713-22.

5. Demierre MF, Gan S, Jones J, etal. Significantimpact of cutaneous T-cell lymphoma on patients' quality of life: results of a 2005 National Cutaneous Lymphoma Foundation Survey. Cancer. 2006;107(10):2504-11.

6. Agar NS, Wedgeworth E, Crichton S, et al. Survival outcomes and prognostic factors in mycosis fungoides/Sézary syndrome: validation of the revised International Society for Cutaneous Lymphomas/European Organisation for Research and Treatment of Cancer staging proposal. J Clin Oncol. 2010;28(31):4730-9.

7. Virmani P, Zain J, Rosen ST, et al. Hematopoietic stem cell transplant for mycosis fungoides and Sézary syndrome. DermatolClin. 2015;33(4):807-18.

8. Pierce JM, Mehta A. Diagnostic, prognostic and therapeutic role of CD30 in lymphoma. Expert Rev Hematol. 2017;10(1):29-37.

9. Diamandidou E, Colome-Grimmer M, Fayad L, et al. Transformation of mycosis fungoides/Sezary syndrome: clinical characteristics and prognosis. Blood. 1998;92(4):1150-9.

10. Scarisbrick JJ, Prince HM, Vermeer MH, et al. Cutaneous lymphoma international consortium study of outcome in advanced stages of mycosis fungoides and sezary syndrome: effect of specific prognostic markers on survival and development of a prognostic model. J Clin Oncol. 2015;33(32):3766-73.

11. Arulogun SO, Prince HM, NgJ, et al. Long-term outcomes of patients with advanced-stage cutaneous T-cell lymphoma and large cell transformation. Blood. 2008;112(8):3082-7.

12. Younes A, Yasothan U, Kirkpatrick P. Brentuximab vedotin. NatRev Drug Discov. 2012;11(1):19-20.

13. https://www.fda.gov/drugs/resources-information-ap proved-drugs/fda-approves-brentuximab-vedotin-treat ment-adult-patients-primary-cutaneous-anaplastic-largecell. Accessed on February 20th, 2020

14. https://www.ema.europa.eu/en/documents/variationreport/adcetris-h-c-002455-ii-0048-epar-assessmentreport-variation_en.pdf. Accessed on February 20th, 2020

15. Prince HM, Kim YH, Horwitz SM, et al. Brentuximab vedotin or physician's choice in CD30-positive cutaneous T-cell lymphoma (ALCANZA): an international, openlabel, randomised, phase 3 , multicentre trial. Lancet. 2017;390(10094):555-66.

16. Kim YH, Tavallaee M, Sundram U, et al. Phase II investigator-initiated study of brentuximab vedotin in mycosis fungoides and Sézary syndrome with variable CD30 expression level: a multi-institution collaborative project. J Clin Oncol. 2015;33(32):3750-8.
17. Duvic M, Tetzlaff MT, Gangar P, et al. Results of a phase II trial of brentuximab vedotin for CD30+ cutaneous T-cell lymphoma and lymphomatoid papulosis. J Clin Oncol. 2015;33(32):3759-65.

18. www.clincialtrials.gov, accessed on March 30th, 2020

19. Wu XS, Lonsdorf AS, Hwang ST. Cutaneous T-cell lymphoma: roles for chemokines and chemokine receptors. J Invest Dermatol. 2009;129(5):1115-9.

20. Iellem A, Mariani M, Lang R, et al. Unique chemotactic response profile and specific expression of chemokine receptors CCR4 and CCR8 by CD4(+)CD25(+) regulatory T cells. J Exp Med. 2001;194(6):847-53.

21. Ni X, Jorgensen JL, Goswami M, et al. Reduction of regulatory $\mathrm{T}$ cells by mogamulizumab, a defucosylated anti-CC chemokine receptor 4 antibody, in patients with aggressive/ refractory mycosis fungoides and Sézary syndrome. Clin Cancer Res. 2015;21(2):274-85.

22. https://www.ema.europa.eu/en/medicines/human/EP AR/poteligeo. Accessed on February 26th, 2020

23. https://www.fda.gov/drugs/resources-information-appro ved-drugs/fda-approves-mogamulizumab-kpkc-mycosisfungoides-or-sezary-syndrome. Accessed on February 26th, 2020

24. Kim YH, Bagot M, Pinter-Brown L, et al. Mogamulizumab versus vorinostat in previously treated cutaneous T-cell lymphoma (MAVORIC): an international, open-label,randomised, controlled phase 3 trial. Lancet Oncol. 2018;19:1192-204.

25. Battistella M, Leboeuf C, Ram-Wolff C, et al. KIR3DL2 expression in cutaneous T-cell lymphomas: expanding the spectrum for KIR3DL2 targeting. Blood. 2017;130:2900-2.

26. Marie-Cardine A, Viaud N, Thonnart N, et al. IPH4102, a humanized KIR3DL2 antibody with potent activity against cutaneous T-cell lymphoma. Cancer Res. 2014;74(21):6060-70.

27. Bagot M, Porcu P, Marie-Cardine A, et al. IPH4102, a firstin-class anti-KIR3DL2 monoclonal antibody, in patients with relapsed or refractory cutaneous T-cell lymphoma: an international, first-in-human, open-label, phase 1 trial. LancetOncol. 2019;20(8):1160-70.

28. Kantekure K, Yang Y, Raghunath P, et al. Expression patterns of the immunosuppressive proteins PD-1/CD279 and $\mathrm{PD}-\mathrm{L} 1 / \mathrm{CD} 274$ at different stages of cutaneous T-cell lymphoma/mycosis fungoides. Am J Dermatopathol. 2012;34(1):126-8.

29. Xia Y, Medeiros JL, Young KH. Signaling pathway and dysregulation of PDl and its ligands inlymphoid malignancies. Biochim Biophys Acta. 2016;1865(1):58-71.

30. Khodadoust MS, Rook AH, Porcu P, et al. Pembrolizumab in relapsed and refractory mycosis fungoides and Sézary syndrome: a multicenter phase II study. J Clin Oncol. 2020;38(1):20-8.

31. Horwitz SM, Koch R, Porcu P, et al. Activity of the PI3K- $\delta, \gamma$ inhibitor duvelisib in a phase 1 trial and preclinical models of T-cell lymphoma. Blood. 2018;131(8):888-98.

Publisher's Note Springer Nature remains neutral with regard to jurisdictional claims in published maps and institutional affiliations. 